\title{
POLÍTICAS DE FORMAÇÃO DOCENTE PARA A EDUCAÇÃo INFANTIL
}

\author{
Teacher training policies for early childhood education \\ Políticas de formación docente para la educación infantil
}

Fabiana Silva Fernandes *

Moysés Kuhlmann Jr. ${ }^{* *}$

\begin{abstract}
Resumo
O artigo trata da política de formação docente para a educação infantil, considerando o contexto de transição das instituições de educação infantil para o setor educacional e o que isso representou em termos de demandas. Inicia o texto tratando de dispositivos legais sobre docência e formação para, em seguida, discorrer sobre perfil do profissional de educação infantil que foi se delineando na década de 2000. Posteriormente, apresenta dados estatísticos sobre a formação docente durante o processo de transição das instituições de educação infantil e os esforços da política indutiva do governo federal, nos anos 2000, para a formação desse profissional. Por fim, discutem-se alguns efeitos das políticas de formação em termos da escolaridade do professor e desafios ainda por enfrentar, como promover processos formativos que contemplem as especificidades da educação infantil e considerar as condições sociais e culturais do professor, seja no processo de formação inicial, seja na continuada, seja na formulação de planos de carreira.
\end{abstract}

PALAVRAS-CHAVE: Educação Infantil. Políticas Educacionais. Formação Docente.

\begin{abstract}
The article deals with the teacher training policy for early childhood education, considering the context of the transition of early childhood education to the educational sector and what it represented in terms of demands. The text begins by dealing with legal provisions on teaching and training to then discuss the profile of the child education professional that was being drawn up in the first decade of the 2000s. Subsequently, it presents statistical data on teacher education during the transition process of the institutions of early childhood education and the efforts of the inductive policy of the federal government, in the years 2000, for this professional formation. Finally, we discuss some effects of education policies in terms of teachers' schooling and challenges still to be faced, such as promoting formative processes that take into account the specificities of early childhood education and consider the social and cultural conditions of the teacher, or in the process of initial and further training and in the formulation of career plans.
\end{abstract}

KEYWORDS: Early Childhood Education. Educational Policies. Teacher Training.

\section{Resumen}

\footnotetext{
s* Doutorado em Educação Escolar na Universidade Estadual Paulista (UNESP-FCLAr). Pesquisadora do Departamento de Pesquisas Educacionais da Fundação Carlos Chagas. E-mail: fsfernandes@ fcc.org.br.

${ }^{* *}$ Doutor em História Social na Universidade de São Paulo (FFLCH-USP). Pós-doutorado em Ciências da Educação, Universidade de Lisboa. Pesquisador do Departamento de Pesquisas Educacionais da Fundação Carlos Chagas. Bolsista Produtividade CNPq. E-mail: mjunior@ fcc.org.br.
} 
El artículo trata de la política de formación docente para la educación infantil, considerando el contexto de transición de las instituciones de educación infantil al sector educativo y lo que eso representó en términos de demandas. Inicia el texto tratando de dispositivos legales sobre docencia y formación para luego discurrir sobre el perfil del profesional de educación infantil que se fue delineando en la década de 2000. Posteriormente, presenta datos estadísticos sobre la formación docente durante el proceso de transición de las instituciones de educación infantil y los esfuerzos de la política inductiva del gobierno federal para la formación de ese profesional. Por último, se discuten algunos efectos de las políticas de formación en términos de la escolaridad del profesor y desafíos aún por enfrentar, cómo promover procesos formativos que contemplen las especificidades de la educación infantil y considerar las condiciones sociales y culturales del profesor, sea en el proceso de formación inicial, sea en la continuada, sea en la formulación de planes de carrera.

PALABRAS CLAVE: Educación Infantil. Políticas Educativas. Formación Docente.

\section{INTRODUÇÃO}

Há 22 anos aprovou-se a Lei de Diretrizes e Bases da Educação Nacional (LDBEN/1996), fruto de uma trajetória de disputas em torno de projetos distintos de educação. Isso explica, em parte, que nas décadas seguintes a lei tenha passado por algumas mudanças substantivas, com a supressão, ampliação e inclusão de artigos, envolvendo desde princípios do que se entende por educação obrigatória, profissionais da educação, educação profissional entre outros, até mecanismos de financiamento da educação.

Em 2009, a Lei $\mathrm{n}^{\circ} 12.014$ alterou a LDBEN, discriminando as categorias profissionais de trabalhadores que são considerados profissionais da educação. Foram considerados os professores com habilidades em nível médio ou superior para docência na educação infantil e, no ensino fundamental e médio, trabalhadores em educação com diploma de pedagogia, com habilitação em administração, planejamento, supervisão, inspeção e orientação educacional, bem como com título de mestrado e doutorado e trabalhadores com diploma de cursos técnico ou superior em área pedagógica. Também no ano de 2009, a Lei 12.056 acrescentou um parágrafo no Título VI, sobre o regime de colaboração para a formação inicial e continuada dos profissionais da educação, aspecto importante que deu respaldo para a Política Nacional de Formação Docente. Complementando esse dispositivo, a Lei 12.796, de 2013, incluiu um novo parágrafo na LDB, que dispõe sobre a necessidade de os entes federativos adotarem mecanismos que facilitem o acesso e a permanência de professores em cursos de formação docente em nível superior, para atuar na educação básica pública.

Em 2017, a Lei 13.415 fez novas inclusões e mudanças na redação da lei, mas no que concerne aos profissionais da educação, manteve, no artigo 62, a modalidade normal, oferecida em nível médio, como formação mínima do docente na educação infantil e nos cinco primeiros anos do ensino fundamental. Vale destacar que a formação em nível médio para professores do ensino fundamental foi admitida nas regiões em que não existem profissionais formados em nível superior.

Houve também um conjunto de ações do governo federal que passaram a estimular a formação docente. A Coordenação Geral da Educação Infantil (Coedi), instância ligada à Secretaria de Educação Básica (SEB) criou subsídios e definiu estratégias para assessorar os entes federativos na oferta de educação infantil e contribuiu para a formação do professor da referida etapa de ensino (NUNES; CORSINO; DIDONET, 2011). Em 2005, a Secretaria de 
Educação a Distância, do MEC, implantou o Proinfantil, para a formação inicial, em nível médio, de professores que não possuíam a qualificação mínima para atuar na educação infantil. Em 2006, as Diretrizes Curriculares Nacionais para o Curso de Pedagogia (BRASIL, 2006) passam a considerar a educação infantil como parte integrante da formação inicial dos futuros professores.

Considerando essas questões, este texto tem por propósito apresentar o perfil dos docentes de educação infantil, no Brasil, e o contexto de formação docente nos últimos 10 anos, elencando as principais iniciativas e esforços que têm sido feitos para garantir uma formação superior e adequada para essa etapa da educação básica.

\section{Profissionais de educação infantil: formação e perfil}

A educação infantil, no Brasil, tornou-se a primeira etapa da educação básica com a aprovação da atual Lei de Diretrizes de Bases da Educação Nacional (Lei 9394/1996). Essa medida foi estabelecida já na Constituição de 1988, que integrou a educação infantil ao sistema educacional, definindo ser direito da criança de 0 a 6 anos de idade o atendimento em creche e pré-escola. E "a inclusão deste direito em diretrizes e normas, na esfera da educação nacional, simboliza uma alteração histórica para a educação infantil no País." (SOUZA; ARAUJO; SILVA, 2017, p. 154)

Com isso, houve uma reconfiguração das instituições e a creche, até então uma denominação referida às instituições de educação infantil para crianças de 0 a 6 anos, vinculadas aos órgãos de assistência, redefiniu-se como a instituição destinada às crianças de 0 a 3 anos, nomeando-se como pré-escola, as instituições educacionais para as crianças de 4 a 6 anos (posteriormente, de 4 a 5 anos), o que contribuiu na luta para a superação dos preconceitos que envolvem a educação assistencialista. (KUHLMANN JR., 2015)

Em 2000, o Conselho Nacional de Educação dispôs, no parecer 04/2000, as normas para a integração das creches à educação, enfatizando os seguintes aspectos normativos: a vinculação das instituições de educação infantil aos sistemas de ensino, a elaboração das propostas pedagógicas, a formação dos professores, dentre outros aspectos. A necessidade de elaboração do parecer, dispondo sobre as Diretrizes Operacionais para a Educação Infantil, surgiu das dúvidas geradas pelo fato de que havia instituições de educação infantil, em especial a creche, que mantinham vínculos com setores do poder público que não a Educação, como a Previdência e a Assistência Social, mas eram de responsabilidade dos sistemas educacionais dos municípios, tal como definido na LDBEN/1996 e na Emenda Constitucional $\mathrm{n}^{\mathrm{o}} 14$, que criou o Fundef.

Apesar dessa iniciativa, foi a partir de 2005 que ocorreu um processo mais efetivo de transferência das creches e instituições que atendiam crianças de 0 a 3 anos da Assistência Social para a Educação. Por iniciativa do Ministério de Desenvolvimento Social e Combate à Fome, do Ministério da Educação, e do Ministério do Planejamento, Orçamento e Gestão, foi instituído um Grupo de Trabalho pela Portaria Interministerial n $n^{\circ} 3.219$, de 21 de setembro de 2005, com o objetivo de apresentar uma proposta que transferiria as ações de apoio financeiro às crianças de 0 a 6 anos atendidas em creches e pré-escolas do Ministério do Desenvolvimento Social e Combate à Fome para o Ministério da Educação. Até então o MDS transferia recursos para as instituições de educação infantil, mediante o Fundo Nacional de Assistência Social. 
O que fundamentava as ações desse grupo de trabalho interministerial era o aporte legislativo educacional e de assistência social, que redefiniam princípios e estruturas organizacionais tanto da pasta da educação, quanto da assistência social. O relatório produzido indicava que o objetivo da transição das instituições de educação infantil da assistência social para a educação visava:

\begin{abstract}
- o cumprimento da legislação vigente - Constituição Federal, Estatuto da Criança e do Adolescente (ECA), Lei de Diretrizes e Bases da Educação Nacional (LDB), Plano Nacional de Educação (PNE); Política Nacional de Assistência Social e Norma Operacional Básica do Sistema Único de Assistência Social (NOB/SUAS);

- o fortalecimento da Política Nacional de Educação Infantil, especialmente no que diz respeito à formação integral das crianças de 0 a 6 anos, à qualidade e à equidade no atendimento educacional a esta faixa etária;

- a consolidação da concepção de Educação Básica;

- o rompimento do ciclo de reprodução intergeracional da pobreza na medida em que a educação infantil contribui para a formação adequada das novas gerações de brasileiros, em especial os que pertencem aos grupos menos favorecidos da sociedade;

- a consolidação das funções específicas da assistência social no campo da proteção social básica, em consonância com a Política Nacional de Assistência Social e a implementação do Sistema Único da Assistência Social, assim como apontar ações articuladas entre a assistência social e a educação. (MPOG; MDS; MEC, 2006, p. 6)
\end{abstract}

Destaca-se que um dos argumentos em favor da transição é a importância da educação infantil para todas as crianças na faixa etária do 0 a 6 anos de idade, deixando de discriminar o atendimento educacional das populações vulneráveis. Reconhece-se o direito das crianças à educação, seja pelas conquistas expressas em documentos normativos importantes como o Estatuto da Criança e do Adolescente, em 1990 e a LDBN 9394/1996, seja pelos avanços na produção do conhecimento, que mostram a importância da educação infantil para o desenvolvimento afetivo, cognitivo e social da criança.

Além disso, a LDBEN 9394/1996, nas disposições transitórias, indicava a inadequação da existência de instituições de educação infantil na assistência social, determinando, no artigo 89, que "as creches e pré-escolas existentes ou que venham a ser criadas deverão, no prazo de três anos a contar da publicação desta lei, integrar-se no respectivo sistema de ensino". Isso deveria ter ocorrido até dezembro de 1999, mas em 2005, havia instituições de educação infantil ligadas à assistência social e não contabilizadas nos Censos Escolares realizados pelo Inep.

As implicações desse processo vão desde os esforços para expandir o atendimento, à definição de normas para a elaboração de propostas educativas específicas para lidar com a faixa etária correspondente, até a formação dos profissionais que trabalham nas instituições.

Quanto à cobertura de atendimento da educação infantil, ela não contemplava nem $50 \%$ da população na faixa etária de 0 a 6 anos, conforme dados do IBGE de 2004 e quanto mais nova a criança, menor a taxa de atendimento. Esse cenário ainda é negativo especialmente para as creches e para as crianças mais novas. Conforme o Censo Demográfico de 2010 , apenas $23 \%$ das crianças brasileiras de 0 a 3 anos estavam matriculadas em creche.

Em relação à pré-escola, houve um avanço no atendimento, mais expressivo a partir de 2009. Ademais, a Lei ${ }^{\circ} 12.796$, de 4 de abril de 2013, que alterou a LDB e estabeleceu a obrigatoriedade da educação para a faixa etária de 4 a 17 anos teve um efeito sobre o crescimento das matrículas para as crianças de 4 a 5 anos (FERNANDES; DOMINGUES, 
2017). No estado de São Paulo, por exemplo, a cobertura em pré-escola é significativamente maior que o da creche e, em 2012, a taxa de atendimento estava em torno de $94 \%$ da população de 4 e 5 anos em creche e de $38 \%$ das crianças de 0 a 3 anos.

No entanto, considerar a faixa etária de 0 a 3 anos como um grupo homogêneo em termos de acesso á educação é um equívoco, porque são as crianças de 2 e 3 anos que estão matriculadas nas creches, conforme o gráfico 2 apresenta:

Gráfico 1 - Distribuição das crianças de 0 a 3 anos do Estado de São Paulo, segundo a faixa etária detalhada por situação de frequência a Educação Infantil e dependência administrativa

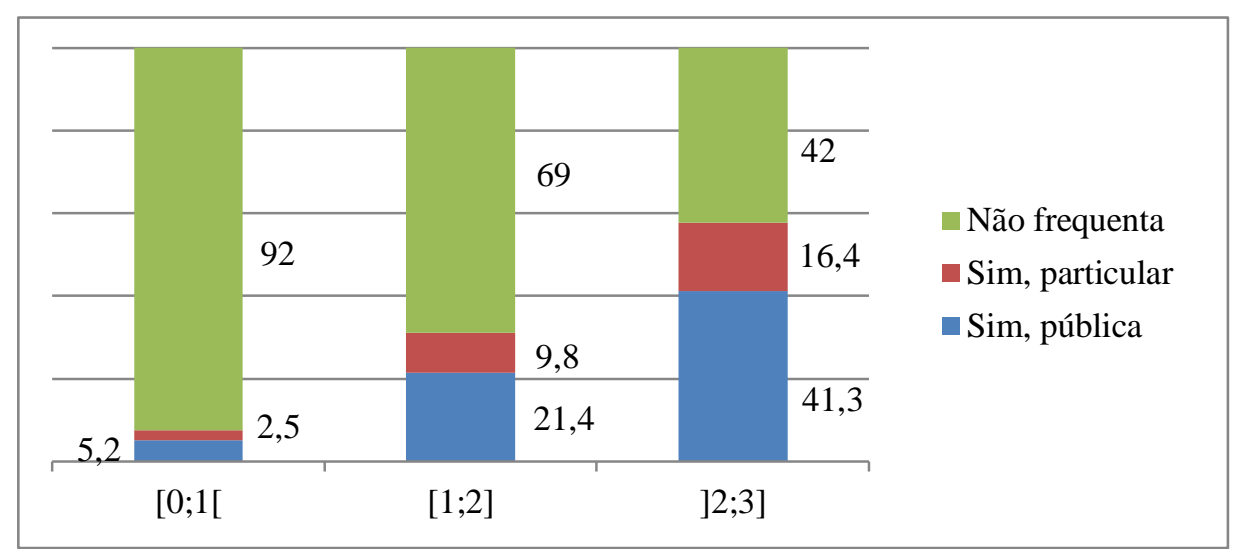

Fonte: FERNANDES, DOMINGUES, 2017, p. 155

Especialmente no que se refere às creches, até a definição da LDBEN, não era exigida uma formação específica aos profissionais que trabalhavam com as crianças: não possuíam a formação em nível médio e um número expressivo de pessoas não tinha ensino fundamental completo (FREITAS, 2007).

Em 1996, dados do Censo Escolar indicam que a formação das funções docentes da educação pré-escolar ${ }^{1}$ em cada uma das regiões brasileiras era distinta e nas regiões mais pobres, a formação era mais precária. No Gráfico 2, observa-se que, em relação aos profissionais que tinham ensino de Primeiro Grau Incompleto, a região Nordeste liderava, contendo $80 \%$ de professores nessa condição, seguida da região Norte, com $10 \%$ deles nessas condições. Em números absolutos isso significa que, de 16.198 docentes brasileiros que trabalhavam na educação Pré-Escolar e que tinham formação de Primeiro Grau incompleta, 13.116 estavam na região Nordeste, 1.644, na região Norte e o restante, 1.338 profissionais distribuíam-se entre as demais regiões.

Gráfico 2: Número de Funções Docentes na Educação Pré-escolar, por grau de formação - 1996 (\%)

\footnotetext{
${ }^{1}$ O termo educação infantil passou a ser adotado no Censo Escolar de 1999. Até então, a referência que se fazia à etapa era educação pré-escolar.
} 


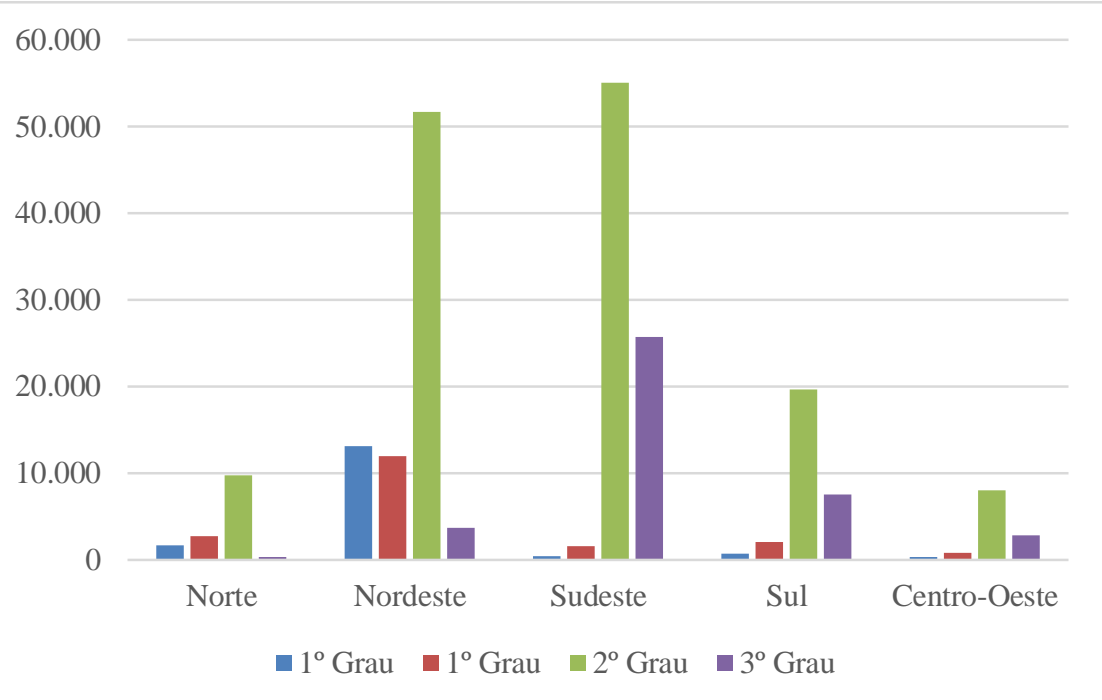

Fonte: Inep - Censo Escolar 1996. Elaboração própria

Quanto ao grupo de funções docentes com ensino superior completo, a região Sudeste apresentava o maior número de profissionais nessa condição $(60 \%$ dos profissionais com ensino superior estavam na região Sudeste), seguida da região Sul. Em números absolutos, significa que, entre o grupo de 40.061 profissionais que possuíam Ensino de Terceiro Grau ${ }^{2}$ completo, 25.733 estavam no Estado de São Paulo.

Classificando o conjunto de funções docentes na Educação Pré-escolar, no Brasil, por nível de formação, verifica-se que do total de 219.517 profissionais, 144.189 , ou seja, $66 \%$ tinham a formação em nível médio (segundo grau).

Gráfico 3 - Funções docentes de Educação Pré-escolar, no Brasil, por formação (1996)

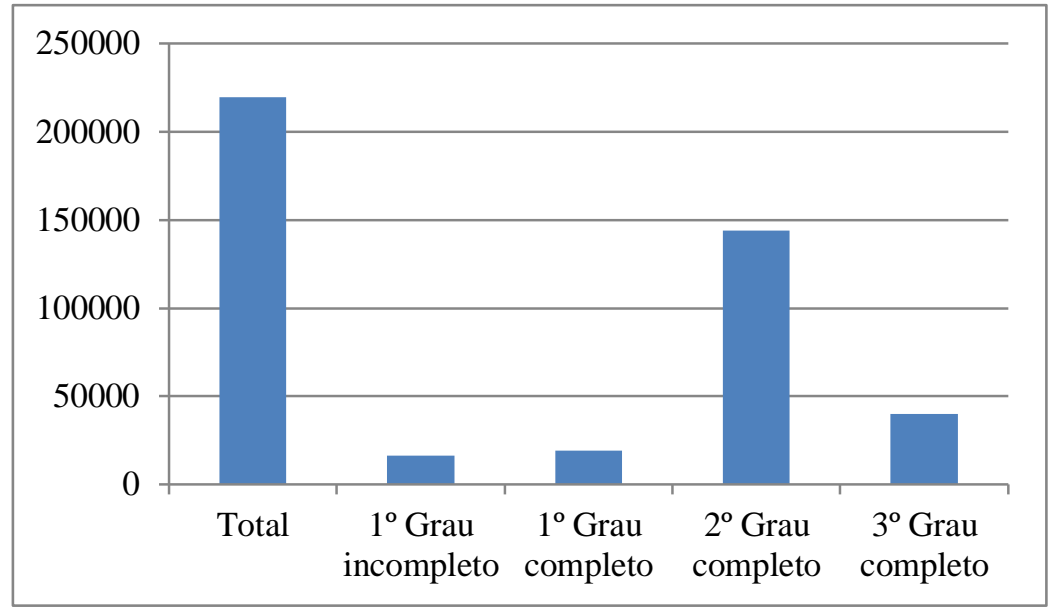

Fonte: Inep - Censo Escolar 1996. Elaboração própria

\footnotetext{
${ }^{2}$ Até a aprovação da LDBEN2397/1996, a nomenclatura utilizada para as diferentes etapas da educação eram ensino de primeiro grau (atual ensino fundamental), ensino de segundo grau (atual ensino médio) e ensino de terceiro grau (ensino superior).
} 
Em 2004, quando o processo de transição das creches se intensificou, verifica-se que, de um total de 75.275 funções docentes das creches, apenas 7,26\% possuíam o ensino fundamental. Na pré-escola, 2,3\% de 293.698 docentes estavam nessa situação. Considerando que esses dados são do Censo Escolar de 2004, esse percentual poderia ser maior se as instituições não cadastradas no setor educacional fossem contabilizadas.

O número maior de professores habilitados na pré-escola em comparação com os da creche está em consonância com o percurso histórico da educação infantil, uma vez que o atendimento em creche se expandiu na área da assistência social, sem exigência de um profissional com uma habilitação específica. Já a pré-escola, que se desenvolveu no âmbito da educação, demandou profissionais habilitados para o exercício do magistério. (MPOG; MDS; MEC, 2006, p. 09)

Os gráficos 4 e 5 indicam as diferenças de formação entre os docentes de creche e préescola, no ano de 2005, quando o processo de transição das instituições de educação infantil estava em curso, do Ministério do Desenvolvimento Social para a Educação.

No gráfico 4, verifica-se que havia cerca de 85 mil docentes atuando em creche e que mais da metade deles possuíam ensino médio completo.

\section{Gráfico 4 - Número de Funções Docentes em Creche, por Nível de Formação, no Brasil (2005)}

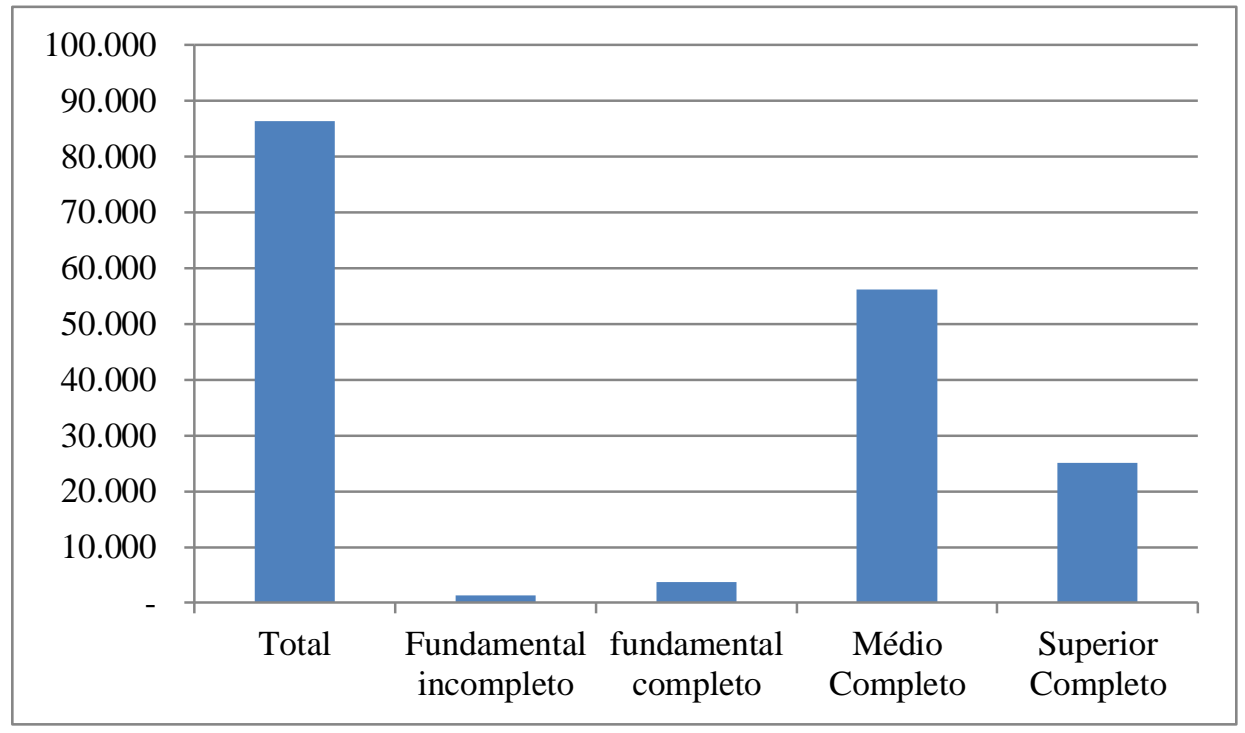

Fonte: Inep - Censo Escolar 2005. Elaboração própria

Em relação à pré-escola, o gráfico 5 indica a existência de pouco mais de 300 mil docentes atuando e que quase $100 \%$ deles possuíam ou ensino médio completo ou ensino superior. Apenas uma parcela muito pequena possuía ensino fundamental completo.

Gráfico 5 - Número de Funções Docentes em Pré-escola, por Nível de Formação, no Brasil (2005) 


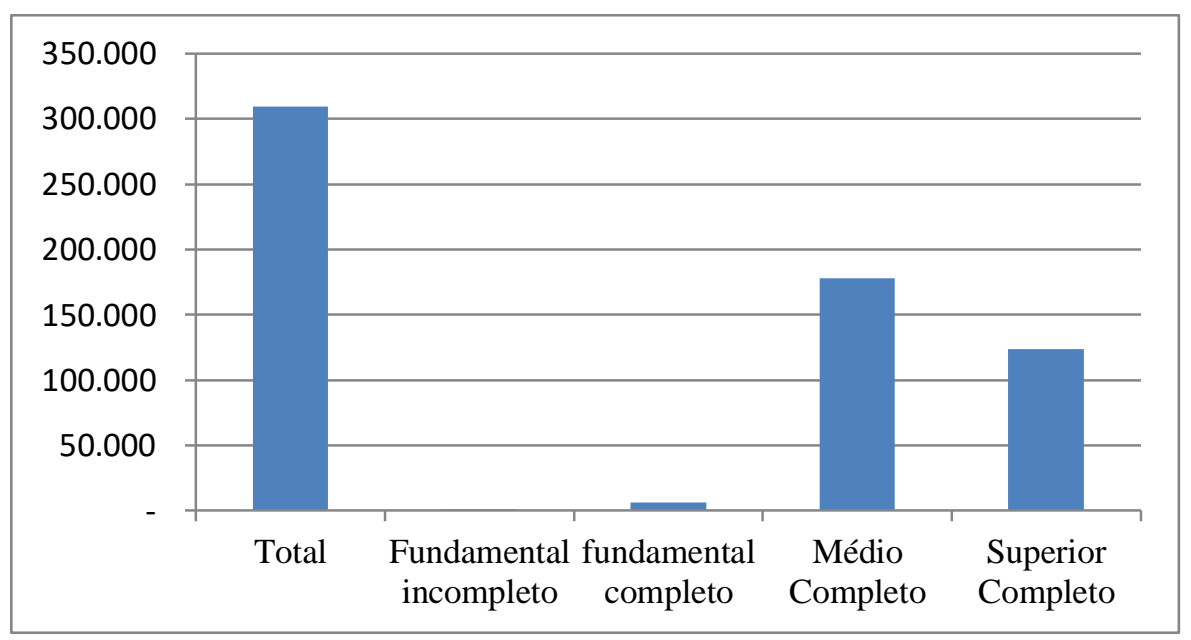

Fonte: Inep - Censo Escolar 2005. Elaboração própria

\section{Formação dos professores de educação infantil: quais políticas de valorização?}

A transferência das instituições de educação infantil e a expansão da oferta de vagas aumentaram a demanda por professores qualificados e a adoção de estratégias que contemplassem tanto a formação inicial desses profissionais, quanto a formação continuada.

Em pesquisa desenvolvida sobre a gestão da Educação Infantil no Brasil (CAMPOS et al.; 2011; FERNANDES; CAMPOS, 2015) verificou-se a redefinição de planos de carreira e da identificação de cargos em extinção, para reenquadrar os funcionários que permaneceram nas instituições de educação infantil, quando da transição, assim como os esforços para que esses trabalhadores tivessem uma formação mínima para lidar com a rotina pedagógica e com a educação das crianças. É possível que, no momento atual, não existam mais os antigos cargos oriundos da assistência social, seja pelo processo de reenquadramento funcional, seja pela aposentadoria dos funcionários que permaneceram na antiga função, até a sua completa extinção. No entanto, nos últimos 20 a 30 anos, a formação inicial e continuada dos professores de educação infantil era uma medida necessária.

Foram diversas as estratégias criadas para a habilitação de professores leigos: desde cursos presenciais, cursos semi-presenciais modulares a cursos à distância, viabilizados pelo Decreto $\mathrm{n}^{\circ}$ 2.494, de 1997, regulando a oferta de cursos a distância e pela Resolução $\mathrm{n}^{\circ} 2$, de 1997, do Conselho Nacional de Educação, que permitia a oferta de programas especiais de formação pedagógica.

A habilitação em nível médio, especialmente no caso da Educação Infantil, teve os estados como entes federativos centrais, na medida em que eram incumbidos da autorização de cursos desse nível.

Mas, em 2005, o Ministério da Educação criou um programa de caráter emergencial, o ProInfantil, para formar os professores em exercício, sem a habilitação mínima exigida. Sendo um programa de nível médio, na modalidade Normal, destinou-se a professores de creches e pré-escolas públicas e privadas (filantrópicas e comunitárias). Foi realizado em parceria com universidades públicas, dentro de um curso de carga horária de 3.200 horas, distribuídas em quatro módulos semestrais de 800 horas cada, com a duração de dois anos. $\mathrm{O}$ objetivo era atingir 32 mil professores em exercício e sem habilitação. 
Gatti, Barreto e André (2011) questionaram a eficácia do ProInfantil, uma vez que, em $2009,1,3 \%$ dos professores nessa etapa da educação eram leigos e se perguntaram se a oferta regular desse programa não seria um incentivo para os entes federativos contratarem professores sem habilitação.

A Universidade Aberta do Brasil foi outro instrumento de implementação de políticas de formação inicial de professores, em nível superior, instituído pelo Decreto ${ }^{\circ} 5.800$, em 08 de junho de 2006. Em 2011, havia 92 IES que integravam a UAB e, atualmente, há por volta de 70 instituições espalhadas pelo país.

A formação continuada dos professores ganhou maior visibilidade após a aprovação da Lei 9.424/1996, que instituiu o Fundo de Manutenção e Desenvolvimento do Ensino Fundamental e de Valorização do Magistério (Fundef), mas o foco ainda era o Ensino Fundamental. O Fundef e, posteriormente, o Fundeb, criaram as condições institucionais para a elaboração de políticas de valorização do magistério, destinando $60 \%$ dos recursos educacionais dos entes federativos para isso. O fortalecimento do FNDE como instância de financiamento da educação nacional também foi uma estratégia importante, particularmente para o destino de recursos a programas de formação docente, articulados com os demais entes federativos (GATTI; SÁ BARRETO; ANDRÉ, 2010).

A formação de professores em serviço era responsabilidade de estados e municípios, mas contou com o papel indutor e a assistência técnica da União, para que isso pudesse ser viabilizado. A criação do Plano de Desenvolvimento da Educação, em 2007, foi uma das frentes que estimulou o processo de formação de professores. Havia uma meta no PDE, que era habilitar professores em exercício por meio de programa de formação em serviço, articulados com instituições de ensino superior, com a cooperação técnica e financeira da União e dos Estados.

Outras medidas indutoras foram a alteração da estrutura da CAPES, pela Lei 11.502, de 2007, que ampliou a responsabilidade do órgão pela formação docente e pela estruturação de um sistema nacional de formação do professor. Destaca-se também a formulação da Política Nacional de Formação de Profissionais do Magistério da Educação Básica, instituída pelo decreto $n^{\circ}$ 6.755, de 2009, que previu a instalação de Fóruns Estaduais Permanentes de Apoio à Formação Docente e fomento a programas de formação inicial e continuada dos profissionais da rede pública de educação básica. No entanto, a atuação dos fóruns parece não ter ocorrido a contento e faltam estudos que permitam compreender como essas instâncias têm desempenhado seu papel.

Finalmente, houve a elaboração do Plano Nacional de Formação de Professores de Educação Básica, o PARFOR, constituído por um conjunto de ações do Ministério da Educação, com a colaboração das Secretarias de Educação de Estados e Municípios e Instituições de Ensino Superior para ministrar cursos superiores a professores em exercício em escolas públicas que não possuíam a formação adequada prevista pela LDB. O PARFOR integrava o Plano de Ações Articuladas (PAR) no bojo do Plano de Desenvolvimento da Educação.

Ainda não há estudos que indiquem o efeito das políticas de formação sobre o nível de escolaridade dos professores, mas os dados de 2017 mostram uma mudança ainda bastante tímida em relação à escolaridade dos professores que atuam na educação infantil.

O gráfico 6 mostra que ainda há professores com ensino fundamental incompleto. Embora a proporção de indivíduos dessa categoria seja 0\%, ainda existem docentes que atuam 
sem a formação mínima, no Brasil, duas décadas depois de aprovação do FUNDEF e, posteriormente do FUNDEB, em que a valorização do magistério é um aspecto imprescindível e previsto no orçamento da educação.

\section{Gráfico 6 - Escolaridade dos docentes que atuam na Educação Infantil - 2017}

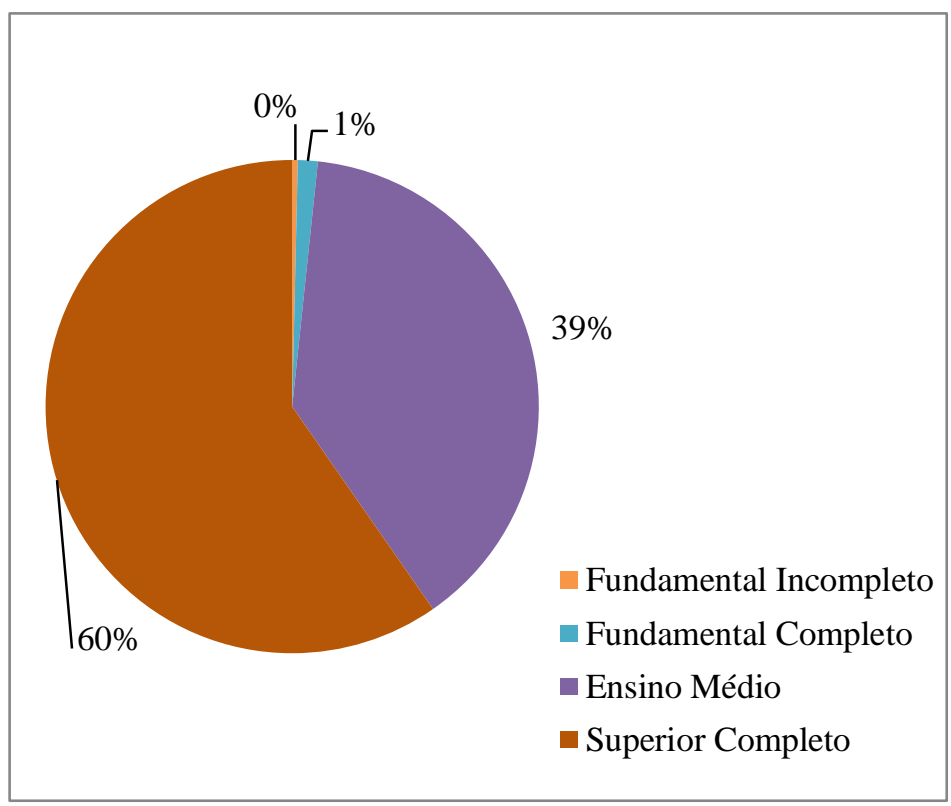

Fonte: Inep - Censo Escolar 2017. Elaboração própria

Cabe destacar que os docentes que atuam em creches contribuem para a permanência desse cenário e que $2 \%$ deles possuem o ensino fundamental completo.

Gráfico 7 - Escolaridade dos docentes que atuam em creche - Brasil/2017

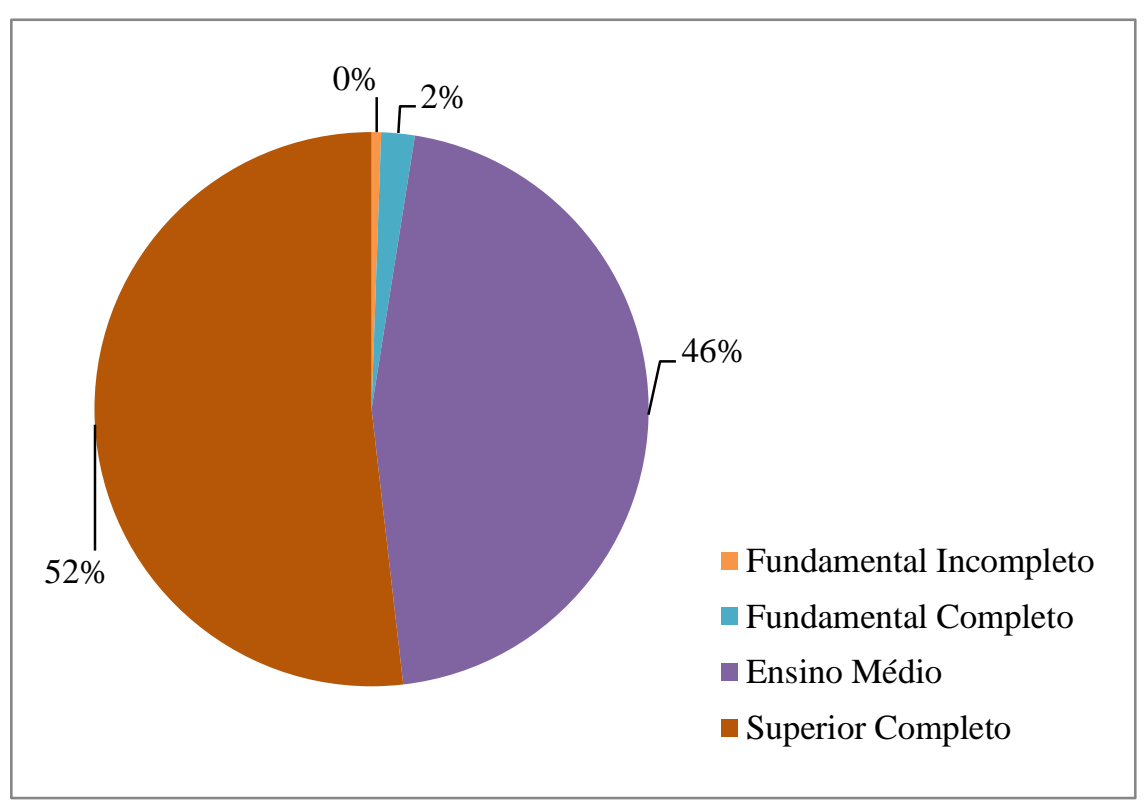

Fonte: Inep - Censo Escolar 2017. Elaboração própria 
A formação inicial dos professores deve receber atenção especial, não somente porque há docentes que ainda não atingiram a escolaridade mínima para o exercício do magistério, mas porque uma formação sólida é um dos elementos para a melhoria da qualidade da educação. No entanto, ao longo desses últimos anos, além das iniciativas do governo federal e de demais esferas de governo, houve uma proliferação de cursos de baixa qualidade com um currículo que não atende especificidades da educação infantil e não promove a articulação entre o conhecimento pedagógico e a prática docente, com grande diversidade de formatos institucionais, como escolas normais superiores, universidades, faculdades, institutos e cursos à distância. (FREITAS, 2007)

Gatti, Sá Barreto e André (2010) chamam a atenção também para o fato de que além da formação inicial, as próprias condições socioeconômicas e culturais dos professores devem ser levadas em consideração, como forma de aplacar desvantagens sociais:

\begin{abstract}
No que diz respeito à atuação dos professores na educação básica para a superação das condições produtoras de marginalização e exclusão dentro e fora das redes de ensino, seu papel, no intuito de oferecer às crianças e aos jovens aprendizagem significativas para superar desvantagens sociais, sem dúvida é importante. Porém, esse papel está atrelado às suas próprias condições sociais de trabalho, aí incluídas suas características socioeconômicas e culturais, estruturas de carreira e salário e sua formação básica e continuada (p.28)
\end{abstract}

Nesse sentido, na formação docente, seja a inicial, seja a continuada, e na elaboração dos planos de carreira, deve-se levar em consideração que os professores são provenientes de camadas sociais menos favorecidas, em especial os professores de Educação Infantil e primeiros anos do Ensino Fundamental (GATTI; SÁ BARRETO; ANDRÉ, 2010)

\title{
CONSIDERAÇÕES FINAIS
}

A educação infantil, com a promulgação da Lei de Diretrizes e Bases da Educação Nacional (LDBN 9394/1996), conquistou uma posição de relevância no cenário educacional brasileiro, compondo a primeira etapa da educação básica.

Dificuldades persistem nessa trajetória que vem sendo construída para a educação infantil, como a falta de escolaridade mínima de professores que atuam nessa etapa de ensino.

No caso das creches, ainda que o marco legal reconheça os profissionais que atuam nelas como professores, a formação desses profissionais é mais baixa, as instituições que formam esses professores são mais precárias e sua formação inicial não atende as necessidades de atuação, o que impacta diretamente na qualidade do atendimento oferecido para as crianças de 0 a 3 anos.

Outras questões que não foram discutidas no texto poderiam ser levantadas, como a pouca atratividade da carreira e dos salários e as condições de trabalho, inclusive a formulação de planos de carreira diferenciados para essa categoria de professores, como encontrado em pesquisa realizada por Malta e outros (2011). A análise da existência de quadros profissionais distintos no interior das creches, principalmente, em que convivem auxiliares de educação infantil e professores exercendo a função docente, poderia trazer outros elementos para se avaliar as políticas destinadas a esse nível educacional (ALVARENGA, 2009; CONCEIÇÃO, 2010; OLIVEIRA, 2017). 
Abordar a questão das políticas de formação de professores é ter por horizonte a melhoria da qualidade da educação, articulada com outros elementos que são importantes para se avançar:

\begin{abstract}
Valorização social da profissão, os salários, as condições de trabalho, a infraestrutura das escolas, as formas de organização do trabalho escolar, as carreiras que devem fazer parte de uma política geral de apoio aos docentes. São múltiplos os fatores que não podem ser esquecidos, nem desconsiderados no delineamento de políticas para professores (GATTI; SÁ BARRETO; ANDRÉ, 2011, p. 15).
\end{abstract}

Nesse sentido, ainda que avanços tenham sido obtidos, perduram desafios importantes que atravessam as duas décadas de existência da LDBEN/1996: a universalização do acesso às crianças de 4 e 5 anos, a ampliação de vagas para a faixa etária dos 0 a 3 anos, a formação inicial e continuada dos professores e a elaboração de planos de carreiras que garantam a paridade e que sejam atrativos.

\title{
REFERÊNCIAS
}

ALVARENGA, V. C. A profissionalização do trabalho docente: um estudo das condições de trabalho de professoras de pré-escola, 2009. 169f. Dissertação (Mestrado em Educação) Faculdade de Ciências e Letras, Universidade Estadual Paulista "Júlio de Mesquista Filho", Araraquara, 2009.

CAMPOS, M. M.; ROSEMBERG, F.; FERREIRA, I. M. Creches e pré-escolas no Brasil. São Paulo: Cortez, Fundação Carlos Chagas, 1992.

CAMPOS, M. M. et al. A gestão da Educação Infantil no Brasil (Relatório Final). São Paulo: Fundação Carlos Chagas; Fundação Victor Civita, 2011.

CONCEIÇÃO, G. P. de. Trabalho docente na educação infantil pública de Florianópolis: um estudo sobre as auxiliares de sala, 2010. 218f. Dissertação (Mestrado em Educação) - Centro de Ciências da Educação, Universidade Federal de Santa Catarina, Florianópolis, 2010.

GATTI, B. A.; BARRETTO, E. S. S.; ANDRÉ, M. E. D. A. Politicas docentes no Brasil: um estado da arte. Brasília, DF: UNESCO, 2011. 300p.

SOUZA, G. M. A. de; ARAÚJO, G. C. de O.; SILVA, W. C. da. Vinte anos da Lei n. ${ }^{\circ}$ 9.394/96, o que mudou? Políticas educacionais em busca de democracia. Revista Retratos da Escola, Brasília, v. 11, n. 20, p. 147-160, jan./jun. 2017. Disponível em:

<http://www.esforce.org.br/>. Acesso em 12 de novembro de 2018.

BRASIL; MPOG; MEC; MDS. Relatório dos Trabalhos realizados pelo GT criado pela Portaria Interministerial № 3.219, de 21 de Setembro de 2005, e Proposta de Prorrogação das suas atividades. Brasília: 2006. Disponível em:

<http://portal.mec.gov.br/seb/arquivos/pdf/Educinf/eduinfport3219_05.pdf>. Acesso em: 18 de dezembro de 2018.

BRASIL. Constituição (1988). Constituição da República Federativa do Brasil. Brasília: Senado Federal, 1988.

BRASIL. Lei $n^{\circ}$ 9.394, de 20 de dezembro de 1996. Estabelece as diretrizes e bases da educação nacional. Diário Oficial da União, Brasília, 23 dez. 1996. Disponível em: < http://www.planalto.gov.br/ccivil_03/leis/19394.htm>. Acesso em: 20 de dezembro de 2018. 
BRASIL. CNE. Resolução $C N E / C P N^{o} 1$, de 15 de maio de 2006. Institui Diretrizes Curriculares Nacionais para o Curso de Graduação em Pedagogia, licenciatura. Brasília, 2006. Disponível em: <http://portal.mec.gov.br/cne/arquivos/pdf/rcp01_06.pdf>. Acesso em: 20 de dezembro de 2018.

FERNANDES, F.S.; CAMPOS, M. M. Educação Infantil no Brasil: reflexões sobre a supervisão e a gestão de recursos humanos. RBPAE, v. 31, n. 2, p. 27-292, maio/ago. 2015.

FREITAS, H. C. L. de. A (nova) Política de Formação de Professores: a prioridade postergada. Educ. Soc. Campinas, vol.28, n.100 - Especial, p.1203-1230, out.2007.

NUNES, M. F. R; CORSINO, P; DIDONET, V. Educação infantil no Brasil: primeira etapa da educação básica. Brasília: UNESCO, MEC/SEB, Fundação Orsa, 2011.

OLIVEIRA, T. G. de. Docência e Educação Infantil: condições de trabalho e profissão docente. Dissertação (Mestrado em Educação). 173f. Faculdade de Educação, Universidade Estadual de Minas Gerais, Belo Horizonte, 2017.

KUHLMANN JR., M. Infância e educação infantil: uma abordagem histórica. 7. ed., Porto Alegre: Mediação, 2015.

Recebido em: 09/05/2019

Aprovado em: 12/07/2019 